mendations regarding the safety of magnetic resonance imaging that are included in a recent publication of the Medical Devices Directorate. ${ }^{1}$

Non-magnetic dental implants are harmless, as are intrauterine and diaphragm contraceptive devices. Some penile and inflatable breast implants may, however, be hazardous. ${ }^{5}$ Prosthetic heart valves are compatible with magnetic resonance imaging, ${ }^{5}$ although they were originally believed not to be so.

Metal fragments introduced accidentally, including pellets, bullets, or shrapnel, may be a contraindication, particularly soon after introduction. ${ }^{6}$ This applies particularly to intraocular foreign bodies, and permanent loss of vision in one eye due to preretinal haemorrhage has been reported. ${ }^{7}$ The risk with intraocular fragments is greater with high field magnets, but exposing any patient with a suspected orbital foreign body is unwise; metal workers may not know that they are at risk. Metal detectors similar to those in airports may be too insensitive, but if an orbital foreign body is invisible in a high quality radiograph then probably no appreciable risk exists. ${ }^{8}$ Most retinal tacks (excluding the martensitic steel Western European model) ${ }^{9}$ and intraocular lens mounts ${ }^{10}$ seem safe, but eyelid springs are not. ${ }^{4}$

This list of contraindications to magnetic resonance imaging is not exhaustive, and anything not included here is not necessarily innocuous. Confusion is exacerbated by anecdotal horror stories (from which even official hazard notices ${ }^{11}$ may not be immune), and full details of any disaster should be widely and responsibly circulated.

IVAN MOSELEY Consultant radiologist

National Hospital for Neurology and Neurosurgery,

Queen Square,

London WC1N 3BG

1 Medical Services Directorate. Guidelines for magnetic resonance diagnostic equipment in clinical use. London: HMSO, 1993.

2 Pavlicek $W$, Geisinger $M$, Castle $L$. The effects of nuclear magnetic resonance on patients with cardiac pacemakers. Radiology 1993;147:149-53.

3 Abrams HL. Cochlear implants are a contraindication to MRI. fAMA 1989;261:46.

4 Johnson GC. Need for caution during MR imaging of patients with aneurysm clips. Radiology 1993;188:287-8.

5 Shellock FG, Morisoli S, Kanal E. MR procedures and biomedical implants, materials and devices: 1993 update. Radiology 1993;189:587-9.

6 Teitelbaum GP, Yee CA, Van Horn DD, Kim HS, Colletti PM. Metallic ballistic fragments: MR imaging safety and artifacts. Radiology 1990;175:855-9.

7 Kelly WM, Paglen PG, Pearson JA. Ferromagnetism of intraocular foreign body causes unilateral Kelly WM, Paglen PG, Pearson JA. Ferromagne
blindness after MR study. AFNR 1986;7:243-5.

blindness after MR study. AFNR 1986;7:243-5.
8 Williamson TH, Smith FW, Forrester JV. Magnetic resonance imaging of intraocular foreign bodies. Brf Ophthalmol 1989;73:755-8.

9 Albert DW, Olson KR, Parel JM, Hernandez E, Lee W, Quencer R. Magnetic resonance imaging and retinal tacks. Arch Ophthalmol 1990;105:1479-80.

10 De Keizer RJW, Te Strake L. Intraocular lens implants (pseudophakoi) and steelwire sutures: a contraindication for MRI. Doc Ophthalmol 1986;61:281-4.

11 Medical Devices Directorate. Hazard Notice (93)39. London: MDD, 1993.

\title{
Children's consent to treatment
}

\section{Listen to the children - they will have to live with the decision}

\begin{abstract}
I would like to see the age limits completely scrapped, and maturity brought in. As you grow up, your age has a stereotype. I'm trying to escape from that stereotype."-Robin, aged 13-quoted in "Children's Consent to Surgery"
\end{abstract}

If competent to understand the consequences should a child be able to consent and, more importantly, refuse to consent to medical treatment? Some recent rulings in the English law courts have apparently disenfranchised children, and the debate has resurfaced on their rights to self determination. The issue has a tremendous impact on paediatric practice, and all those who care for children should have a clear understanding of the legal and ethical consensus.

From the late 1960s to the early 1990s changes in the law on consent progressively increased the rights of those under 18 to self determination-always dependent on their capacity to understand the implications of their decisions. The case of Gillick $v$ West Norfolk and Wisbech Area Health Authority established that children under 16 years could give legally effective consent to medical treatment, independent of their parents' wishes, provided they had sufficient understanding and intelligence. ${ }^{2}$

The position was reversed in 1992 in the case $\operatorname{Re} \mathrm{W}$, an orphaned girl in a children's home who refused to eat. She was forcibly tube fed until her 16th birthday, when she applied to the courts to allow her the adult right to refuse treatment. Lord Donaldson ruled that no one under 18 years has an absolute right to make his or her own decisions on medical treatment, especially when that decision is refusal. ${ }^{3}$ Many commentators saw this decision as setting back English children's rights by 30 years. Some pointed to the "Catch 22" created-patients whose competence is in question are found rational and able to give consent if they accept the advice of the doctor; but are judged incompetent if they reject that same advice. ${ }^{4} \mathrm{Re} \mathrm{W}$ may have been an extraordinary case, but the ruling could be viewed as a licence to bulldoze children into treatment regardless of their personal wishes, fears, or capacity to understand the implications of their decisions.

Children do have some rights from international and national legislation. The United Nations Convention on the Rights of the Child advocates the right of every child to self determination, dignity, respect, non-interference, and the right to make informed decisions. The European charter for children in hospital states that "children and parents have the right to informed participation in all decisions involving their health care. Every child shall be protected from unnecessary medical treatment and investigation." The Children Act of 1989 states that children's wishes and feelings should be incorporated into the decision making concerning them. ${ }^{6}$ In theory, the pronouncements of the United Nations and of the European Charter are at variance with the current English law.

In practice in almost all circumstances this apparent conflict will not matter.

Clearly those rare life and death decisions in which a minor refuses treatment must be resolved in the courts. That does not eliminate the medical professionals' responsibility carefully to consider the views of the child in conjunction with those of the parents or guardians. If there is an impasse, however, it is law that is equipped to judge whether a child fully understands the implications of such a decision, in which case the opinion of doctors or parents could be overturned. Only when the decision is so urgent that it calls for virtually immediate action might it fall to the parents and doctors to go ahead with treatment regardless of the child's wishes. In all but these most extreme cases, however, it should be mandatory to secure a child's consent to treatment in addition to that of the parents, provided that the child has the capacity to understand the implications of assent or refusal.

The crucial question is, then, when does a child have the capacity to make such decisions? There is no simple answer to this. In her recent book Priscilla Alderson gives data on 120 
children undergoing paediatric orthopaedic surgery; she discusses the age when patients, parents, and health professionals thought that children could-decide for themselves whether they wanted surgery that was not life saving. The children themselves set the highest threshold age for self determination at 14 years; the parents put it slightly lower at 13.9 years; and, remarkably, the health professionals chose the lowest figure, $10 \cdot 3$ years. ${ }^{1}$

While the age of informed consent remains contentious, an attempt should be made fully to explain the procedures and potential outcomes to the child, as stated by the European charter, even if the child is too young to be fully competent. After all, it is the child who will have to live with the outcome of the decision. One of the many themes running through Alderson's book is the dismay and anger expressed by children who felt cheated by the explanations, or lack of them, from parents and clinicians. Children who are legally too young to give consent to treatment must still be treated as individuals whose rights as members of society are not solely dependent on the legal definition of the day. Before accepting any consent the clinician responsible must be sure that both child and parents understand, to the best of their capacity, what is entailed-so enabling them to make a collective, considered decision. The doctor should be able to show that the views of the child were taken into account and write notes to that effect in the child's health records.

In all but the most life threatening circumstances it amounts to an abuse of a child's rights as a member of society to disregard a refusal to consent to treatment if the child seems to have made a fully informed and considered decision. This is especially true in the 1990s-for with the classic family unit having so often disintegrated the child may have a more stable and balanced viewpoint than either parent.

J P H SHIELD Research fellow

JD BAUM

Professor of child health

Institute of Child Health,

University of Bristol, Bristol BS2 8BJ

1 Alderson P. Children's consent to surgery. Buckingham: Open University Press, 1993:9.

2 [1986] AC 112.

3 Re W [1992] 3 WLR 758.

4 Devereux JA, Jones DPH, Dickenson DL. Can children withhold consent to treatment? BMf 1993;307:1459-61.

5 Alderson P. European charter of children's rights. Bulletin of Medical Ethics 1993:13-5.

6 The Children Act 1989. London: HMSO, 1989.

\section{Autosomal dominant polycystic kidney disease}

\section{The discovery of a second locus may improve our understanding of cyst formation}

When the $B M \mathcal{F}$ last published an editorial on adult autosomal dominant polycystic kidney disease ${ }^{1}$ there was no chromosomal assignment for the disorder. Two have since been recognised. The first, designated $\mathrm{PKD}-1,{ }^{2}$ has been localised to a narrow region of about half a million base pairs on the short arm of chromosome 16 , but the specific gene has not yet been discovered. A second locus was postulated in $1988,{ }^{3}$ and in the past few months two groups have independently confirmed that a second locus exists on chromosome $4 \mathrm{q} 13$ q23. ${ }^{45}$ What proportion of cases that this new locus accounts for and whether other loci exist are unknown.

The discovery of this second locus will improve the accuracy of presymptomatic testing and may be of prognostic significance. The disorder associated with the PKD-1 locus seems to have a more aggressive clinical course with earlier onset, more rapid progression to renal failure and hypertension, and earlier age of death than that associated with the second locus. ${ }^{6}$ Cardiovascular deaths are more common in patients with autosomal dominant polycystic kidney disease than in the general population. ${ }^{7}$ They are also commoner in patients with polycystic disease undergoing dialysis than in patients without polycystic disease undergoing dialysis. ${ }^{8}$

The identification of the second locus may improve our understanding of the underlying mechanism of cyst formation. Renal cystic change may result from many stimuli and is present in several different inherited renal disorders. In this context the recent discovery of a gene responsible for tuberous sclerosis close to the PKD-1 locus on chromosome 16 is interesting. ${ }^{9}$ As renal cysts are part of the clinical spectrum of tuberous sclerosis, advances in this disease may throw light on the pathogenesis of cystic development of polycystic kidney disease.

Several chemical toxins have been incriminated in the development of cysts in mice that are morphologically indistinguishable from those of the CPK mouse, an animal model for recessive polycystic kidney disease. Abnormal fluid accumulation associated with mislocation of the sodium-potassium ATPase pump has also been implicated. ${ }^{10}$ Currently, the most likely mechanism is an abnormal growth factor or receptor that leads to the proliferation of the renal tubular cells, and several observations support this hypothesis. Firstly, in vitro cultures of polycystic kidney epithelium show increased cell division." Secondly, left ventricular mass, which strongly predicts premature cardiovascular death, is significantly increased in asymptomatic subjects with autosomal dominant polycystic kidney disease before the onset of hypertension or renal dysfunction..$^{12}$ Increased or abnormal cellular proliferation may be responsible for this. Thirdly, the regression of cystic change within a polycystic kidney after transplantation into a non-polycystic host suggests that a circulating factor may affect the cystic change. ${ }^{14}$ Finally, the location of the second locus contains several candidate genes that regulate growth. According to Kimberling et al the endothelin 1 receptor gene may be one such candidate gene as it is expressed in the appropriate renal tissue and is located in the correct region of chromosome. ${ }^{45}$

Early diagnosis of adult autosomal dominant polycystic kidney disease improves the diagnosis and management of complications. ${ }^{15}$ Along with the previously mentioned cardiac abnormalities, this strengthens the case for considering intervention studies. For example, low protein or low sodium diets reduce cyst size in one strain of rats (Han:SPRD-CY) with autosomal dominant inherited cystic kidneys. Any intervention studies would clearly have to weigh benefit against the necessity for earlier diagnosis using genetic markers, before cysts form. The evidence for and increased recognition of potentially treatable early abnormalities in asymptomatic subjects with polycystic 